\title{
The sinking problem of humanity: a shark Fin's tale
}

\section{Opinion}

While swimming in the ocean, a stereotypical shark fin breaks the surface. The immediate instinct is to dart for shore while the theme song for Jaws plays in one's mind. Duh Dun.... The fame of Jaws in the 1970's romanticized the primal fear of a shark attack while rewarding the killing of the so-called brutal, man-eating antagonist. For years since the release of Jaws, man in real life, has actively hunted any shark he encountered. This is no longer a Hollywood production, but stars real life actors with real life sharks paying with their lives. And, the situation has grown worse ever since.

Bycatch and shark-finning, results of human activity, are among the leading causes of the reduced shark populations that are being observed. Bycatch is the term used when an animal is unintentionally caught by fishermen. This refers to sharks, but also includes other sea life such as turtles, whales, and dolphins. Large nets are deployed, often for several hours, to purposely ensnare large numbers of wildlife. These large nets will catch anything from small fish like anchovies, to turtles and sharks, commonly all in the same net. Unfortunately, many sharks need to swim continually in order to survive, so by the time they are brought onboard, they have already died. Another common fishing gear is the longline, comprised of a single fishing line equipped with hundreds of hooks, and designed to catch anything that can eat the attached bait. For sharks, this has a similar effect as the large nets, because most suffocate before they can be released.

So, what happens when sharks are found dead? Some are thrown back into the ocean, but more often they are finned. Shark finning is a large industry where sharks are intentionally, or unintentionally, caught, and their fins are removed. The rest of the body is thrown overboard, often still alive, and they sink to the bottom of the ocean without the ability to swim. The fins are then sold to various countries, mostly in the Eastern Pacific, for shark fin soup. Shark fin soup is considered a delicacy in many Asian cultures, making it an expensive commodity. Because of its social status, consumers are willing to pay the fishermen well for providing the fins.

Unfortunately, bycatch is only a small portion of the fin trade. Many fishermen in the Eastern Pacific actively search for species like

\author{
Volume 7 Issue 2 - 2018
}

\section{Jacquelyne M Reuder}

Department of Marine Biology, Nova Southeastern University, USA

Correspondence: Jacquelyne M Reuder, Department of Marine Biology, Nova Southeastern University, USA, Email jr2863@mynsu.nova.edu

Received: February 17, 2018 | Published: March 07, 2018

Hammerheads, Oceanic White tip, and Blue sharks. With increased awareness in recent years, laws are now being passed to make finning illegal in several countries and their surrounding waters. With the vastness of the ocean however, not all waters are claimed or protected. This allows fishermen to enter international waters to fish and then send their catch wherever there is a market for them. Thankfully, several airlines and international couriers have banned the transport of fins in their cargo (i.e.- American Airlines, FedEx, and UPS).

Sharks are man-eating monsters, you say. Why should we care, you say? Sharks are a kind of animal that is essential for maintaining the ecological balance in the ocean. Sharks eat other animals that eat other animals that eat other animals, and so on. Without sharks, populations of some animals and organisms that reproduce quickly, often explode. Then they eat everything around them, leaving little for other species, and the cycle continues down the food chain. When this happens, fishermen can't catch the fish that we love so much to eat (i.e.- salmon, shrimp, scallops). And what about those cute dolphins and whales that we love to see? They won't be around either, because they will have nothing to eat. When you go on vacation to go snorkeling, what will you see? Not much anymore. So, what do we really want? Do we prefer good food, healthy marine animal life, and a healthy ocean, or delicacies, social status for some, and more money? 